\title{
Adolescent Religiosity and Selective Exposure to Television
}

\author{
Piotr S. Bobkowski \\ Doctoral student \\ School of Journalism and Mass Communication \\ University of North Carolina at Chapel Hill
}

Submitted for publication in the Journal of Media and Religion

\begin{abstract}
Relying on the Adolescent Media Practice Model and selective exposure theory, this study investigated whether religious adolescents watch less mature television entertainment programs than their less religious peers. Program maturity was measured using V-chip ratings, with higher maturity scores indicating content that included more sexuality, violence, and/or adult and sexual language. The responses from 1,335 16- to 18-year-olds who completed Wave 2 of the National Study of Youth and Religion (NSYR) survey were analyzed. Findings indicate that religiosity contributes to explaining the variance in television maturity means, with more religious adolescents indicating a preference for less mature television entertainment. Gender, race, income, and parents' monitoring of teens' media were also found to influence television maturity. Teens' attitudes toward premarital sex appeared to mediate the effect of religiosity on their television entertainment choices.
\end{abstract}


Despite the recent proliferation of new media options, television continues to be the default medium to which children and teenagers are drawn (Lemish, 2007). The average U.S. adolescent lives in a household with three television sets and spends more than three hours daily watching television (Roberts, Foehr, \& Rideout, 2005). At the same time, researchers and advocacy groups concerned with the socializing influence of television warn of the detrimental effects that violent and sexual content might have on the well-being of young audiences (e.g., Parents Television Council, 2007).

Scholars have long asserted the potentially harmful consequences of exposure to mature media content by young people. Exposure to violent (Bushman \& Huesman, 2001; Carnagey \& Anderson, 2005) and sexual (Brown et al., 2006) media content has been shown to lead to undesirable outcomes. As indicated by the U.S. V-chip standards, adult language and sexual dialogue are also considered harmful to younger audiences (Center for Media Education, 1999).

All youth do not choose to watch the same television shows. Previous studies have shown that moods as well as social identities such as sex and race correlate with the types of programs that teens select (e.g., Livingstone, 1990; Brown \& Pardun, 2004). Religiosity has also been shown to serve as a robust predictor of a wide range of health and social outcomes (Benson \& King, 2005; Regnerus \& Smith, 2005). Smith (2005), for instance, found significant differences between religious and nonreligious teenagers "across every outcome measure examined: risk behaviors, community participation, media consumption, sexual activity, and emotional well-being” (p. 218-219).

As it does with other risk behaviors, religiosity might play a shielding role in adolescents' exposure to potentially detrimental television content. Relying on the 
theoretical perspectives of the Adolescents' Media Practice Model and selective exposure theory, this paper argues that religiosity plays a role in teenagers' television entertainment choices.

\section{Literature Review}

\section{Adolescents' Media Practice Model and selective exposure}

This investigation draws on the assumptions of Steele and Brown's (1995) Adolescents' Media Practice Model, which conceptualizes adolescents as being intentional about their media selections. Brown (2000) wrote that adolescents "choose media and interact with media based on who they are or who they want to be" (p. 35). Crucial to the present study are two of the model's assumptions: (1) that adolescents are active agents in their media choices and effects, and (2) that adolescents' media selections are intimately entwined with their continuous identity development. The model has served as the theoretical grounding for analyses of adolescents' bedroom culture (Steele \& Brown, 1995), selective media diets (Brown \& Witherspoon, 2001), sexual development (Brown, Steele, \& Walsh-Childers, 2002), music preferences (Schwartz \& Fouts, 2003), and exposure to pornography (Peter \& Valkenburg, 2006). The model encompasses a series of established media theories (Steele \& Brown, 1995), including selective exposure.

Selective exposure, the proposition that individuals systematically rely on their biases to view and avoid certain media messages, is rooted in Festinger's (1957) notion of cognitive dissonance. Festinger argued that consonance between individuals' cognition and behavior is natural and desired. When knowledge inconsistent with behavior is introduced (sometimes by way of the media), individuals experience dissonance, which 
they will endeavor to diminish and avoid from escalating. Festinger predicted that individuals will respond to dissonance by adjusting their behavior, modifying their thoughts, and/or exposing themselves selectively to external information. Applying these notions to a mass communication context, Klapper (1960) wrote that "people tend to expose themselves to those mass communications that are in accord with their existing attitudes and interests" (p. 19).

Initial empirical evidence did not consistently support the existence of selective exposure. Within a decade of Festinger's articulation of cognitive dissonance, Freedman and Sears (1965; Sears \& Freedman, 1967) critically assessed the findings that were used in support of selective exposure. Research into the phenomenon continued, however. When Cotton (1985) presented a systematic summary of selective exposure research, he argued that newer work, having addressed the methodological shortcomings of earlier studies, had shown more confirmatory results.

At present, the theory supports two distinct research approaches. The first of these is rooted in the research tradition of social psychology, from which selective exposure originally emerged. These studies rely on experimental methods to manipulate and measure variables in single-exposure study designs. The recent research stream by Dolf Zillmann and his students illustrates this approach (e.g., Knobloch, Hastall, Zillmann, \& Callison, 2003). These researchers have primarily focused on selective exposure to online news articles, manipulating article elements and measuring the effects of individual respondent differences such as self-esteem and gender-role orientation (KnoblochWesterwick \& Alter, 2007; Knobloch-Westerwick, Brück, \& Hastall, 2006; KnoblochWesterwick \& Hastall, 2006) on readers' preferences. Focusing on entertainment media, 
they have also measured selective exposure to socially defiant music as a function of rebelliousness and disinhibition (Carpentier, Knobloch \& Zillmann, 2003); and studied gender and culture-based differences in children's preferences for entertainment videos (Knobloch, Callison, Chen, Fritzsche, \& Zillmann, 2005).

While experimental studies contribute to establishing the causal effects of media characteristics or psychological variables, ecological validity of such studies is limited to only short-term, laboratory-based effects. The second stream of recent selective exposure work has focused on both individual and social variables to assess exposure to political communication over time. Drawing on interview data (Chaffee, Saphir, Graf, Sandvig, \& Hahn, 2001) and survey results (Bennett, 2002; Best, Chmielewski, \& Krueger, 2005; Bimber \& Davis, 2003), these studies have used variables such as political ideology (Bennett, 2002; Chaffee et al., 2001; Graf \& Aday, 2008; Stroud, 2007), political involvement (Chaffee et al., 2001; Graf \& Aday, 2008), political interest and media use (Bennett, 2002), and support for the administration of George W. Bush (Best et al., 2005; Stroud, 2007), to investigate respondents' selective preferences for political media messages.

The present study aligns itself with the approach and methods used by the latter of these research streams. It responds to the call of those scholars (e.g., Stroud, forthcoming) who argue that experimental selective exposure research should be supplemented with studies that examine more than a single instance of media selection. Studies of television entertainment programming choice, such as this one, more commonly have been approached from the uses and gratifications perspective (Rubin, 2002). Atkin (1985) linked the two theoretical traditions by situating selective exposure to entertainment 
programming within the uses and gratifications paradigm. He argued that selective exposure is the means by which the anticipated use of viewing (or not viewing) a television program is attained. For instance, a viewer might opt to watch a program to strengthen a certain predisposition, and, similarly, she may opt not to expose herself to a different program to avoid a negative reaction. These psychological goals may be shaped by social influences, such as family structure or religious institutions.

It is appropriate, therefore, for selective exposure studies to examine both psychological and social variables that might affect media choice. Indeed, Davies (2007) tested a model that predicted affinity for television and television use from psychological gratification variables and social variables that reflected the influence of a moral authority. Working with a sample of Brigham Young University students, Davies found that loyalty to moral authority was negatively related to affinity for television, while gratification measures were positively related to affinity for the medium.

The present research draws on the principles of selective exposure to suggest that religious teenagers tend to avoid cognitive dissonance by selectively exposing themselves to television content that does not undermine their religiously-based principles. The expectation is that religiosity plays a role in youths' entertainment choices above and beyond demographic, socioeconomic, and parental variables.

\section{Religiosity}

Research has generally supported the proposition that religious people engage in selective exposure. People who identify themselves as religious have been found to watch television less frequently, and tend to watch more innocuous television shows than nonreligious people. Tankard and Harris (1980) found that heavy television viewers were 
less likely to identify themselves as religious and to report frequently attending religious services. Jackson-Beeck and Sobal (1980) showed that heavy television viewers were less likely than average television viewers to be members of church-affiliated groups. Applying cognitive dissonance and uses and gratifications theories, Hamilton and Rubin (1992) found that religious conservatives watched less sexually-oriented television shows (but not violent shows) than non-conservatives; and that conservatives were less motivated to watch television voyeuristically, that is, with sexual ends in mind.

Recent studies investigating the correlations between religiosity and media use among adolescents likewise support the selective exposure hypothesis in terms of amount of usage and content viewed. Based on a survey of seventh- and eighth-graders, Thomsen \& Rekve (2003) found that religious adolescents watched significantly less television per day (3.18 hours), as compared to their less religious peers (3.72 hours). Likewise, in a study of 13- to 17-year-olds, Smith (2005) found that religiously-committed teens used less media - television, action video games, R-rated movies, and Internet pornography than did nonreligious teens. Religious teens watched less television (1.8 hours/weekday; 4.4 hours/weekend), than religiously-disengaged teens (2.5 hours/weekday; 5.4 hours/weekend). They also played action video games less frequently (1.2 hours/week) than nonreligious teens (4.1 hours/week). R-rated movies made up the majority of the movies watched for a smaller proportion of religious teens (14\%) than religiouslydisengaged teens (42\%). Finally, a larger majority of religiously-devoted teens $(96 \%)$ than nonreligious teens (76\%) never used the Internet to view pornographic sites. Smith's (2005) study provided ample support for the proposition that religious young people spend less time viewing mature media than their less religious peers. But Smith's 
analyses focused on measures of time spent viewing certain types of media and not, as does this study, on preferences for specific television programs. Additionally, Smith did not address the maturity of television content, which is the unique focus of the present analysis. Program maturity indicates sexual and/or violent content, or language that is deemed to be adult and/or sexual in nature (Center for Media Education, 1999). Given this conceptualization, the research reviewed here suggested the following hypothesis: H 1a: Religious adolescents will be more likely than less religious adolescents to watch less mature television programs.

Scholars have also suggested that specific faith communities may influence their members' media use. Schultze (1996), for instance, wrote about Evangelical leaders' denunciation of secular media for undermining the values of their tradition. Smith (1998) found U.S. Evangelicalism to encourage religious commitment more than other Protestant groups. Several studies have also analyzed media use by members of the Church of Jesus Christ of Latter Day Saints (LDS) (e.g., Davies, 2007; Scott, 2003), in light of admonitions about the influence of secular media by that faith group's leadership. Based on the established focus on these two faith traditions, the following two hypotheses were also proposed:

H 1b: Evangelical adolescents will be more likely than non-Evangelical adolescents to watch less mature television programs.

H 1c: Mormon adolescents will be more likely than non-Mormon adolescents to watch less mature television programs.

Given that less has been written about media use and other faith traditions, the following research question also was posed: 
RQ 1: Will adolescents who are members of other faith traditions (Mainline Protestant, Catholic, Jewish), be more or less likely to watch less mature television programs?

\section{Parental and demographic variables}

Research has shown that adolescents' religiosity is highly correlated with parental religiosity (Benson, Donahue, \& Erickson, 1989). This assertion was borne out in Smith's (2005) research, which indicated that between $72 \%$ and $78 \%$ of teenagers held beliefs that were very similar or somewhat similar to those of their parents. Smith also reported that teenagers tended to be affiliated with the same religious traditions as their parents, and that of those who attended religious services, $45 \%$ attended with both parents, while an additional $21 \%$ attended with one parent. The influence of parental religiosity on their children's identity and behavior - both religious and otherwise - must therefore be taken into consideration when analyzing the relationship between teenagers' religiosity and media practices. The following hypothesis was proposed:

H 2a: The children of more religious parents will watch less mature television programs. As the relationship between teenagers' religiosity and television exposure was investigated, controls for the potential moderating effects of age, gender, race, household income, and the extent to which parent(s) monitor teens' media use were also considered. These variables have been shown to play a role in the amount and type of television programming that young people consume (Brown \& Pardun, 2004; Comstock \& Paik, 1991; Comstock \& Scharrer, 2001; Nathanson, 2001). Further, it was assumed that religious parents, themselves likely to watch lower amounts of television and less mature television programming, monitored their children's media use to a greater degree than 
nonreligious parents. It was therefore expected that children of parents who were most religious and who engage in media monitoring will watch the least mature television programs. Following this logic, two hypotheses were tested:

$\mathrm{H} 2 \mathrm{~b}$ : There will be an interaction effect between parental religiosity and parental media monitoring on the maturity of programming watched by adolescents.

$\mathrm{H}$ 2c: There will be an interaction effect between adolescent religiosity and parental media monitoring on the maturity of programming watched by adolescents.

\section{Predispositions to mature programming}

The religious and demographic variables discussed thus far suggest the influence of sociological structures on the viewing preferences of adolescents. But selective exposure is also likely to result from attitudes and psychological predispositions. Atkin's (1985) review, for example, suggested that aggressive individuals were more likely to watch violent programming while nonaggressive individuals avoided it. In a similar way, adolescents who hold more restrictive views about premarital sex may have avoided programming that features sexual content. This suggested the following hypotheses:

H 3a: Adolescents who are less aggressive will be more likely to watch less mature television programs.

H 3b: Adolescents who hold less permissive attitudes about premarital sex will be more likely to watch less mature television programs.

Inasmuch as both a lower predisposition to violence and more conservative attitudes about sex are reflective of religious values (e.g., Regnerus, 2007; Smith, 2005), it was expected that predispositions to less mature television shows would mediate the 
effect of religiosity on the types of shows that adolescents watch. The following hypothesis was proposed:

H 3c: Predispositions toward less mature television programs will mediate the effect of religiosity on the maturity of programs that adolescents watch.

Methods

Sample

To address the research question and hypotheses, the present study relied on National Study of Youth and Religion (NSYR) Wave 2 survey data (for a complete discussion of sampling and survey method, see National Study of Youth and Religion, 2006). NSYR Wave 1 data, collected from July 2002 to April 2003, were based on a telephone survey of a random, nationally representative sample of 3,370 13- to 17-yearolds, the results of which were published in Smith (2005; see also Regnerus, 2005, 2007; Regnerus \& Burdette, 2006; Regnerus \& Uecker, 2006). Using the same sample, Wave 2 survey data were collected from June to November 2005, yielding 2,604 (77\% of Wave 1 sample) valid responses from 16- to 20 -year-olds.

This study used a subsample of 1,335 16- to 18 -year-old Wave 2 respondents (51\% of Wave 2). The narrowing of the sample resulted from NSYR survey design limitations. First, 923 respondents were not asked about their parents' monitoring of their media selections because they were either older than 18 and/or not living with their parent(s). Second, 344 respondents did not provide responses or provided invalid responses for inclusion in the constructed Television Maturity Score (see below). Two additional cases were deleted because the respondents were more than 18 years old. 
The sample included $612(46 \%)$ males and $723(54 \%)$ females. The mean age was $16.9(S D=.82)$. The racial distribution of the analysis sample was: $70.9 \%$ white, $13.9 \%$ black, 9.3\% Hispanic, and 5.9\% other. Chi-square analyses conducted on six of the adolescent-reported variables indicated that the subsample used in this study did not differ significantly from the nationally representative NSYR Wave 2 sample on key measures: Parental Media Monitoring $\left(\chi^{2}=.75, p=.94\right)$, and adolescent's Religious Affiliation $\left(\chi^{2}=6.30, p=.28\right)$, Salience $\left(\chi^{2}=1.09, p=.90\right)$, Attendance $\left(\chi^{2}=6.60, p=\right.$ $.36)$, Prayer $\left(\chi^{2}=3.98, p=.68\right)$, and Scripture Reading $\left(\chi^{2}=3.50, p=.74\right)$.

\section{Measures}

Television Maturity, the primary dependent variable, was based on respondents' three most-watched television programs. Responses consisted of 760 unduplicated program titles, program genres, or network names. Non-entertainment programs (e.g., "evening news"), as well as genres and networks were not used in this analysis, resulting in 605 unique entertainment program titles. These were coded according to their V-chip ratings, using the TV Guide website (www.tvguide.com) and the Internet Movie Database (www.imdb.com) as primary sources. Ratings (TV-Y, TV-Y7, TV-G, TV-PG, TV-14, and TV-MA) were ascertained for 348 (58\%) of the most-watched entertainment programs, and were assigned a value of 1 through 6 , respectively, representing increasing maturity of content. Programs that were identified by more than one rating were assigned an average of those ratings. Rating values for each respondent's television program choices were averaged to compute the score of Television Maturity $(M=4.28, S D=$ .79). Although the efficacy of the V-chip ratings to aid parents in regulating their children's television diets has been seriously questioned (Kunkel et al., 1998; Potter, 
2003), the ratings were useful in providing a comparable metric of maturity for many of the programs.

The Parental Religiosity measure was constructed using two parent-reported NSYR Wave 1 variables: religious salience $(1=$ "not important at all" $\ldots 6=$ "extremely important"); and frequency of attendance at religious services $(1=$ "never" ... $7=$ "more than once a week"; $r(1330)=.63, \mathrm{p}<.001)$. Attendance was standardized to a six-point scale by combining two of its categories ("once a month" and "many times a year"). The mean of these two items yielded the indicator of Parental Religiosity $(M=4.22 ; S D=$ 1.53). Wave 2 teen-reported frequency of parental monitoring of the teen's music, television, and movies ( $1=$ "never" .. 5 = "always"), was used as an indicator of Parental Media Monitoring $(M=2.59, S D=1.23)$.

Five variables were used to measure adolescent religiosity. Religious Affiliation was the type of religious congregation the teen reported attending. Using NSYR categories, adolescents were classified as Evangelical Protestant (34\%), Mainline Protestant (10\%), Catholic (19\%), Jewish (4\%), or LDS (2\%). The remaining 31\% were either of another faith tradition or were not affiliated with a faith tradition. Dummy variables were constructed to assess the potential effect of religious affiliation on programming preferences.

The other four teen religiosity variables were: religious salience $(1=$ "not important at all" $\ldots 5=$ = "extremely important"; $M=4.42, S D=1.82$ ); frequency of attendance $(1=$ "never" $\ldots 7=$ "more than once a week;" $M=3.73, S D=2.24)$; frequency of private prayer $(1=$ "never" $\ldots 7=$ "more than once a day;" $M=3.96, S D=$ $2.00)$; and frequency of private scripture reading $(1=$ "never" $\ldots 7=$ "more than once a 
day;” $M=2.29, S D=1.61)$. An Adolescent Religiosity variable was constructed using the combined mean of the four variables (Cronbach's $\alpha=.83 ; M=3.61, S D=1.57$; salience was standardized to a seven-point scale).

An item indicating the frequency with which, in the past three years, the respondent was involved in a physical fight that resulted in someone getting hurt $(1=$ "never" $\ldots 4=$ "more than five times;" $M=1.45, S D=.78$ ) was used as an indicator of predisposition to Aggression. Two items were combined to yield a measure of Attitude Toward Premarital Sex. A five-category item indicating support for unmarried couples having sex without being in love ( 1 = "strongly disagree" .. 5 = "strongly agree") was collapsed into a dichotomous variable and standardized. It was summed with the dichotomous item indicating support for people abstaining from sex until marriage $(0=$ "yes," $1=$ "not necessarily"). The two items were significantly correlated $r(1,328)=.52$, $\mathrm{p}<.001$ and yielded a variable with a range of $0-2$, which higher values indicating a more permissive attitude toward premarital sex $(M=1.13, S D=.85)$.

Adolescents' Age, Gender ( $0=$ male, $1=$ female $)$, and Race $(0=$ non-White, $1=$ White), as well as household Income (1=less than $\$ 10,000 \ldots 11=\$ 100,000$ and above; reported in NSYR Wave 1) were also assessed.

\section{Results}

Correlation coefficients were computed among the variables and are reported in Table 1. Television Maturity was negatively correlated with Gender, such that males were more likely than females to watch more mature television shows. As expected, the watching of more mature television was significantly negatively correlated with Parental Religiosity, Parental Monitoring of Media, Adolescent Religiosity, and being 
Evangelical. Conversely, Television Maturity was significantly positively correlated with Age, Family Income, being white, being Jewish, and having a more permissive attitude about premarital sex. It was not significantly correlated with being Mormon, Protestant, Catholic, or being more aggressive.

A multiple regression analysis was conducted to predict the Television Maturity mean as a function of demographic variables, parental variables, the hypothesized interactions, adolescent religiosity, and indicators of predisposition to mature content. As presented in Table 2, demographic and parental predictors were entered in the first step of the analysis, adolescent religiosity was entered in the second step, and the predisposition indicators were entered in the third step.

In the first step of the model Gender $(\beta=-.17, p<.001)$ and Parental Monitoring of media use $(\beta=-.07, p<.01)$ contributed significantly to the predictive power of the equation, $R^{2}=.086, F(7,1234)=14.47, p<.001$. Male adolescents were significantly more likely to watch more mature programming, while children of parents who monitored the media were less likely to watch more mature programming. Race $(\beta=.16$, $p<.01)$ and household income $(\beta=.13, p<.001)$ were also significant, although the direction of these two indicators contradicted previous literature (e.g., Comstock \& Scharrer, 2001), with white adolescents and adolescents from wealthier households being more likely to watch more mature programming than non-whites or less well-off teens. Age was not a significant predictor of television maturity. Neither was Parental Religiosity, nor the anticipated interaction between Parental Religiosity and Monitoring. In the second step of the model, with demographic and parental variables held constant, adolescent religiosity $(\beta=-.14, p<.001)$ contributed significantly to the 
predictive power of the equation, $R^{2}$ change $=.02, F(7,1241)=10.25, p<.01$. Thus, Hypothesis 1a was supported, indicating that more religious adolescents tend to watch less mature programming. Neither of the variables indicating Evangelical or Mormon affiliation with specific faith traditions were significant, providing no support for Hypotheses $1 \mathrm{~b}$ and $1 \mathrm{c}$. Likewise, there was insufficient evidence to confidently address RQ 1, which asked if affiliation with other faith traditions (Mainline Protestant, Catholic, Jewish) would affect television maturity.

As the insignificant values for Parental Religiosity and the interaction term between Parental Religiosity and Monitoring in Step 1 indicated, Hypotheses 2a and 2b were not supported. Similarly, Hypothesis $2 \mathrm{c}$ was not supported because the interaction between Adolescent Religiosity and Parental Monitoring also was not statistically significant. The demographic variables that were significant in the first step of the model (gender, race, income, and parental monitoring) remained significant as main effects after the introduction of the interaction term in the second step.

In the third step, with demographic, parental, and religious variables held constant, predispositions to mature programming contributed significantly to the model, $R^{2}$ change $=.006, F(2,1241)=4.68, p<.01$. Although Aggression had no effect, thus not supporting Hypothesis 3a, Attitude About Premarital Sex was significant $(\beta=.10, p<$ .01 ), supporting Hypothesis $3 \mathrm{~b}$. Adolescents who held more permissive attitudes about premarital sex were more likely to watch more mature television programs. Beyond adding to the predictive power of the model, the introduction of the predisposition variables also substantially altered the strength of two variables entered previously. Parental Monitoring became not significant in the third step of the model. Additionally, 
the effect of Adolescent Religiosity weakened considerably, although the variable remained statistically significant $(\beta=-.08, p<.05)$. Combined with the significant contribution of Attitude About Premarital Sex, this provides partial support for Hypothesis $3 \mathrm{c}$. The contribution of the previously significant demographic variables (Gender, Race, Income) remained essentially unchanged.

\section{Discussion}

These findings suggest that religiosity does play a role in adolescents' entertainment television program preferences. The model tested in these analyses explained $11 \%$ of the variance in the maturity of adolescents' favorite television programs. Adolescent religiosity contributed a unique $2 \%$ of the explanatory power. In line with previous studies that investigated the relationship between religion and the media (e.g., Hamilton \& Rubin, 1992), this study provides further evidence that religiosity affects television use. Others (e.g., Smith, 2005; Thomsen \& Rekve, 2003) showed that more religious teens tend to watch less television. Smith (2005) also demonstrated that more religious teens were less likely than their religiously disengaged peers to consume other kinds of more mature media, such as R-rated movies and Internet pornography. The unique contribution of this analysis is its focus on television programming and the maturity of television content consumed by teens. As predicted by selective exposure and related literature, this study demonstrates that more religious teens tend to watch less mature television entertainment shows.

Admittedly, the model tested here did not account for the majority of variability in the television programming choice measure. Predicting media use among adolescents may be particularly tricky. As the Media Practice Model suggests, teens' media choices 
are closely intertwined with the identity development that constitutes the central task of adolescence. Because of the myriad ecological and psychological forces that may affect an adolescent's identity construction and - by extension - his or her media use, a social scientific model can be expected to tap only a limited number of relevant explanatory variables. In proposing a model of adolescents' media diets, Brown and Witherspoon (2001) wrote that teenagers choose some media to be like all of their peers, some media to be like only some of their peers, and some media to be like none of their peers. The results of this study suggest that religiosity, as a marker of identity, affects the types of television programs that some teens include in their media repertoires. The unexplained remaining variance underscores the difficulty of predicting teen behavior in light of the unique identity that each teen strives to construct for him or herself.

If exposure to more mature television programs constitutes a risk for adolescents, then these results fall in line with literature that is finding that religious adolescents engage in fewer risk behaviors than their nonreligious peers (e.g., Benson \& King, 2005; Regnerus \& Smith, 2005). Aiming to clarify the nature of this link, Smith (2005) suggested several social influences that may contribute to positive outcomes in the lives of religious adolescents. Smith wrote that religiosity likely enhances well-being through a faith tradition's moral directives, which are reinforced by a teenager's spiritual experiences, faith-oriented role models, social and organizational ties, and community and personal competencies that are themselves cultivated by the faith tradition. The importance of such supporting social links is underscored by Regnerus (2007), who wrote about the centrality of "plausibility structures" in determining the extent to which 
religious values influence young people's sexual attitudes and behavior. He

conceptualized plausibility structures as

... a network of like-minded friends, family, and authorities who (a) teach and enable comprehensive religious perspectives about sexuality to compete more effectively against ubiquitous sexually permissive scripts, and (b) offer desexualized time and space and provide reinforcement of parental values. ( $p$. 203)

Religious teenagers' inclination toward less mature television programs likely reflects religious values that eschew overt sexuality, profanity, and violence that figure prominently in more mature television programs. From a sociological perspective, the extent to which teens appropriate these values and choose their television programs accordingly is determined by the presence in their lives of experiences, skills, role models, and social ties that reinforce the religious values and the associated television preferences.

Despite this theorized importance of adult support in living out the moral values of a religious tradition, none of the three hypotheses that concerned the influence of parents on adolescents' television choices were supported. Parental influence was evident only in the significance of the Parental Media Monitoring variable in the first two steps of the model. There was no evidence that children of more religious parents watch less mature television programs. There was also no evidence of an interaction between Parental Religiosity or Adolescent Religiosity and Parental Media Monitoring. Parents who monitor their teen's media use appear to have an effect on the maturity of programming that their teens watch, but parents' religiosity does not seem to directly contribute to adolescents' television choices. 
These findings concerning the absence of a direct effect of parental religiosity on teens' programming choices resonate with the results of recent qualitative interviews that Hoover and colleagues (e.g., Hoover, 2006) conducted among families of varying religious backgrounds. Hoover found few differences between families that were more and less religious in their attitudes toward television. This was true of both the programming that these families subscribed to and the roles that parents in these families preferred to enact in their children's watching habits. Hoover (2006) wrote that, "[f]or most families, even ones who clearly identify themselves as distinct in religious terms, there is a powerful set of motivations to consume the same media as everyone else is" ( $p$. 200). With respect to the preferred parenting style, most of the parents tended to agree that it was more important for them to cultivate and model responsible media consumption than to regulate the programs that their children were exposed to. Hoover (2006) found that nearly all parents suggested that "the proper role of parents vis-à-vis media is to equip their children with the skills and values they need to make their own choices, not attempt to protect them from things they should not see" (p. 277).

Hoover's qualitative findings - that a common television culture of viewing and parenting habits cuts across religious differences - help to contextualize the survey results presented here that show no influence of parental religiosity on teens' viewing habits. Further, the weakening effect of parental monitoring on the maturity of programming likely reflects the growing independence of the mid-to-late teenage sample studied here. Indeed, the significant negative correlation between Parental Monitoring and Age (see Table 1) illustrates the weakening role of parents as adolescents progress through their teenage years. This study's findings also suggest that the autonomy in 
television choices that the parents in Hoover's study encouraged for their children was being realized. Despite the weakening of parental monitoring, the teens were making programming choices that were in line with their religious backgrounds.

Expanding the assessment of selective exposure beyond the social measures of demographic and religious influences, this analysis aimed to partially explain the psychological process evident in the effect of religion on television maturity. The inclusion of aggression and attitudes toward premarital sex as predispositions added significantly to the model's explanatory power. The choice of less mature television shows appeared to be mediated by attitudes about premarital sex. This suggests that religious adolescents choose to watch less mature television programs partly because these programs contradict the values concerning sex that are promoted by their faith communities. Hamilton and Rubin (1992) previously found that religiously conservative adults watched less sexually-explicit television shows. In his in-depth interviews Hoover (2006) also found that the most religious parents voiced the most concern about sexual content in the media. The role that attitude about premarital sex appears to play in religious young people's television entertainment choices underscores the centrality of sexual attitudes in differentiating among individuals of diverse religious backgrounds.

The findings reported here suggest that social scientific research that focuses on the effect of religiosity on life outcomes should consider religiosity to be an omnibus measure made up of a range of beliefs and attitudes, along with social skills and relationships, that motivate and restrict the activities their adherents engage in. As Smith (2005) observed, "there is definitely something about religious belief and practice that shapes adolescents' lives in positive directions" (p. 219). This analysis shows that 
attitudes about premarital sex constitute part of the "something about religious belief and practice" that affect teens' exposure to mature television programming.

Some limitations of this study are worth mention. One concern is the reliability of V-chip television ratings as a measure of television program maturity. Potter (2003) has argued that V-chip ratings are a flawed measure of television programming because, among other things, they are developed and assigned by the television networks and because their application is not standardized across programs. Additionally, because not all shows are rated, a number of the shows mentioned by the sampled teens were not included in the analysis. Future research may address this shortcoming by utilizing content analysis and a standard measure to more comprehensively determine teens' media diets. Pardun, L'Engle, and Brown (2005), for instance, offer a blueprint for measuring teens' media use that accounts for both the amount of use and favorite media that includes television programs, songs, movies, and magazines.

Another constraint is this study's cross-sectional design and the resulting inability to ascertain causality. Although selective exposure theory suggests that beliefs shape media choices, a media effects-oriented approach would propose that it is exposure to more mature television programs that diminishes the salience of religious values and beliefs, and leads to lower rates of attendance. Researchers interested in explicating this relationship in more detail should employ more rigorous experimental and longitudinal study designs. Alternately, more nuanced ethnographic approaches may be warranted to fill in the broad strokes drawn by the findings of this survey-based analysis. Recent qualitative research has demonstrated that individual adolescents (Clark, 2003) and families (Hoover, 2006) variously situated along the religious-secular continuum, 
negotiate their relationships with the media in distinct and often unconventional ways. Future research employing in-depth interviews and ethnographic methods, and focusing on teens' television selections vis-à-vis their religious orientations could add texture to the patterns found in this survey.

\section{Acknowledgement}

This research uses data from the National Study of Youth and Religion, a research project designed by Christian Smith, of the Department of Sociology at the University of Notre Dame, that was generously funded by the Lilly Endowment Inc. of Indianapolis, IN.

\section{References}

Atkin, C. K. (1985). Informational utility and selective exposure to entertainment media. In D. Zillmann \& J. Bryant (Eds.), Selective exposure to communication (pp. 157-190). Hillsdale, N.J.: Lawrence Erlbaum.

Bennett, S. E. (2002). Predicting Americans' exposure to political talk radio in 1996, 1998, and 2000. Harvard International Journal of Press/Politics, 7(1), 9-22.

Benson, P. L., Donahue, M. J., \& Erickson, J. A. (1989). Adolescence and religion: A review of literature from 1970 to 1986. Research in the Social Scientific Study of Religion, 1, 153-181.

Benson, P. L., \& King, P. E. (2005). Adolescence. In H. R. Ebaugh (Ed.), Handbook of Religion and Social Institutions (pp. 121-138). New York: Springer Science. 
Best, S. J., Chmielewski, B., \& Krueger, B. S. (2005). Selective exposure to online foreign news during the conflict with Iraq. Harvard International Journal of Press/Politics, 10(4), 52-70.

Bimber, B. A., \& Davis, R. (2003). Campaigning online: The Internet in U.S. elections. New York: Oxford University Press.

Brown, J. D. (2000). Adolescents' sexual media diets. Journal of Adolescent Health, 27S, $35-40$.

Brown, J. D., L’Engle, K. L., Pardun, C. J., Guo, G., Kenneavy, K., Jackson, C. (2006). Sexy media matter: Exposure to sexual content in music, movies, television, and magazines predicts black and white adolescents' sexual behavior. Pediatrics, 117, 1018-1027.

Brown, J. D. \& Pardun, C. J. (2004). Little in common: Racial and gender differences in adolescents' television diets. Journal of Broadcasting \& Electronic Media, 48, 266-278.

Brown, J. D., Steele, J. R., \& Walsh-Childers, K. (2002). Sexual teens, sexual media: Investigating media's influence on adolescent sexuality. Mahwah, N.J.: Lawrence Erlbaum.

Brown, J. D., \& Witherspoon, E. M. (2001). The mass media and adolescents' health in the United States. In Y. R. Kamalipour \& K. R. Rampal (Eds.), Media, sex violence, and drugs in the global village (pp. 77-96). Boulder, CO: Rowman \& Littlefield. 
Bushman, B. J., \& Huesmann, L. R. (2001). Effects of televised violence on aggression. In D. G. Singer \& J. L. Singer (Eds.), Handbook of children and the media (pp. 223-254). Thousand Oaks, CA: Sage.

Carnagey, N. L., \& Anderson, C. A. (2005). The effects of reward and punishment in violent video games on aggressive affect, cognition, and behavior. Psychological Science, 16, 882-889.

Carpentier, F. D., Knobloch, S., \& Zillmann, D. (2003). Rock, rap, and rebellion: Comparisons of traits predicting selective exposure to defiant music. Personality and Individual Differences, 35, 1643-1655.

Center for Media Education. (1999). A parent's guide to the TV ratings and v-chip. Washington, D.C.: Author.

Chaffee, S., Saphir, M. N., Graf, J., Sandvig, C., \& Hahn, K. S. (2001). Attention to counter-attitudinal messages in a state election campaign. Political Communication, 18, 247-272.

Clark, L. S. (2003). From angels to aliens: Teenagers, the media, and the supernatural. New York: Oxford University Press.

Comstock, G., \& Paik, H. (1991). Television and the American child. New York: Acedemic Press.

Comstock, G., \& Scharrer, E. (2001). The use of television and other film-related media. In D. S. Singer \& J. L. Singer (Eds.), Handbook of children and the media (pp. 47-72). Thousand Oaks, CA: Sage. 
Cotton, J. L. (1985). Cognitive dissonance in selective exposure. In D. Zillmann \& J. Bryant (Eds.), Selective exposure to communication (pp. 11-34). Hillsdale, NJ: Lawrence Erlbaum.

Davies, J. J. (2007). Uses and dependency of entertainment television among Mormon young adults. Journal of Media and Religion, 6(2), 133-148.

Festinger, L. (1957). A theory of cognitive dissonance. Stanford, CA: Stanford University Press.

Freedman, J. L., \& Sears, D. O. (1965). Selective exposure. In L. Berkowitz (Ed.), Advances in experimental social psychology (Vol. 2, pp. 58-98). New York: Academic Press.

Graf, J., \& Aday, S. (2008). Selective attention to online political information. Journal of Broadcasting \& Electronic Media, 52(1), 86-100.

Hamilton, N. F., \& Rubin, A. M. (1992). The influence of religiosity on television viewing. Journalism Quarterly, 6, 667-678.

Hill, P. C. \& Hood, R. W. (Eds.). (1999). Measures of religiosity. Birmingham, AL: Religious Education Press.

Hoover, S. M. (2006). Religion in the media age. New York: Routledge.

Jackson-Beeck, M. \& Sobal, J. (1980). The social world of heavy television viewers. Journal of Broadcasting, 24, 5-12.

Klapper, J. T. (1960). The effects of mass communication. New York: The Free Press.

Knobloch, S., Callison, C., Chen, L., Fritzsche, A., \& Zillmann, D. (2005). Children's sex-stereotyped self-socialization through selective exposure to entertainment: 
Cross-cultural experiments in Germany, China, and the United States. Journal of Communication, 55(1), 122-138.

Knobloch, S., Hastall, M., Zillmann, D., \& Callison, C. (2003). Imagery effects on the selective reading of Internet newsmagazines. Communication Research, 30, 3-29.

Knobloch-Westerwick, S., \& Alter, S. (2007). The gender news use divide: Americans' sex-typed selective exposure to online news topics. Journal of Communication, 57(4), 739-758.

Knobloch-Westerwick, S., Brück, J., \& Hastall, M. R. (2006). The gender news use divide: Inpacts of sex, gender, self-esteem, achievement, and affiliation motive on German newsreaders' exposure to news topics. Communications: European Journal of Communication Research, 31, 329-345.

Knobloch-Westerwick, S., \& Hastall, M. (2006). Social comparisons with news personae: selective exposure to news portrayals of same-sex and same-age characters. Communication Research, 33, 262-284.

Kunkel, D., Farinola, W. J. M., Cope, K. M., Donnerstein, E. Biely, E., \& Zwarun, L. (1998). Rating the TV ratings: One year out. Menlo Park, CA: Kaiser Family Foundation.

Lemish, D. (2007). Children and television: A global perspective. Malden, MA: Blackwell.

Livingstone, S. (1990). Interpreting a television narrative: How different viewers see a story. Journal of Communication, 40, 72-85. 
Nathanson, A. I. (2001). Mediation of children's television viewing: Working toward conceptual clarity and common understanding. In W. B. Gudykunst (Ed.), Communication Yearbook 25 (pp. 115-151). Mahwah, NJ: Lawrence Erlbaum.

National Study of Youth and Religion. (2006). Methodological design and procedures for the National Study of Youth and Religion (NSYR) longitudinal telephone survey (Waves 1 \& 2). Retrieved February 1, 2007, from http://www.youthandreligion .org/research/docs/methods_report_only_08.2006.pdf

Pardun, C.J., L’Engle, K., \& Brown, J.D. (2005). Linking exposure to outcomes: Early adolescents' consumption of sexual content in six media. Mass Communication and Society, 8(2), 75-91.

Parents Television Council. (2007). Dying to entertain: Violence on prime time broadcast television 1998 to 2006. Retrieved February 16, 2007, from http://www.parentstv .org/PTC/publications/reports/violencestudy/DyingtoEntertain.pdf

Peter, J., \& Valkenburg, P. M. (2006). Adolescents' exposure to sexually explicit material on the Internet. Communication Research, 33, 178-204.

Potter, W. J. (2003). The 11 myths of media violence. Thousand Oaks, CA: Sage. Regnerus, M. D. (2005). Talking about sex: Religion and patterns of parent-child communication about sex and contraception. The Sociological Quarterly, 46, 81107.

Regnerus, M. D. (2007) Forbidden fruit: Sex and religion in the lives of American teenagers. New York: Oxford University Press.

Regnerus, M. D., \& Burdette, A. (2006). Religious change and adolescent family dynamics. The Sociological Quarterly, 47, 175-194. 
Regnerus, M. D., \& Smith, C. (2005). Selection effects in studies of religious influence. Review of Religious Research, 47, 23-50.

Regnerus, M. D., \& Uecker, J. (2006). Finding faith, losing faith: The prevalence and context of religious transformations during adolescence. Review of Religious Research, 47, 217-237.

Roberts, D. F, Foehr, U. G., \& Rideout, V. (2005). Generation M: Media in the lives of 818 year-olds. Retrieved February 16, 2007, from the Kaiser Family Foundation Web site: http://www.kff.org/entmedia/upload/Generation-M-Media-in-the-Livesof-8-18-Year-olds-Report.pdf.

Rubin, A. M. (2002). The uses-and-gratifications perspective of media effects. In J. Bryant \& D. Zillmann (Eds.), Media effects: Advances in theory and research (2nd ed., pp. 525-548). Hillsdale, N.J.: Lawrence Erlbaum.

Sears, D. O. \& Freedman, J. L. (1967). Selective exposure to information: A critical review. Public Opinion Quarterly, 31, 194-213.

Schwartz, K. D., \& Fouts, G. T. (2003). Music preferences, personality style, and developmental issues of adolescents. Journal of Youth and Adolescence, 32, 205213.

Schultze, Q. J. (1996). Evangelicals' uneasy alliance with the media. In D. A. Stout \& J. M. Buddenbaum (Eds.), Religion and mass media: Audiences and adaptations (pp. 61-73). Thousand Oaks, CA: Sage.

Scott, D. W. (2003). Mormon "family values" versus television: An analysis of the discourse of Mormon couples regarding television and popular media culture. Critical Studies in Media Communication, 20(3), 317-333. 
Smith, C. (with Emerson, M., Gallagher, S., Kennedy, P., \& Sikkink, D.) (1998). American Evangelicalism: Embattled and thriving. Chicago: University of Chicago Press.

Smith, C. (with Denton, M. L.) (2005). Soul searching: The religious and spiritual lives of American teenagers. New York: Oxford University Press.

Steele, J. R., \& Brown, J. D. (1995). Adolescent room culture: Studying media in the context of everyday life. Journal of Youth and Adolescence, 24(5), 551-576.

Stroud, N. J. (2007). Media effects, selective exposure, and Fahrenhait 9/11. Political Communication, 24(4), 415-432.

Stroud, N. J. (forthcoming). Media use and political predispositions: Revisiting the concept of selective exposure. Political Behavior.

Tankard, J. W., Jr., \& Harris, M. C. (1980). A discriminant analysis of television viewers and nonviewers. Journal of Broadcasting, 24, 399-409.

Thomsen, S. R., \& Rekve, D. (2003). The influence of religiosity on reaction to alcohol advertisements and current drinking among seventh and eighth graders. Journal of Media and Religion, 2(2), 93-107. 
Table 1

Correlation coefficients for independent, demographic, parental, religiosity, and predisposition variables

\begin{tabular}{|c|c|c|c|c|c|c|c|c|c|c|c|c|c|c|c|c|}
\hline Variable & $M$ & $S D$ & 1 & 2 & 3 & 4 & 5 & 6 & 7 & 8 & 9 & 10 & 11 & 12 & 13 & 14 \\
\hline $\begin{array}{l}\text { 1. Television } \\
\text { maturity }\end{array}$ & 4.27 & .79 & & & & & & & & & & & & & & \\
\hline $\begin{array}{l}\text { 2. Gender } \\
\text { (1=Female) }\end{array}$ & .54 & .50 & $-.18 * * *$ & & & & & & & & & & & & & \\
\hline 3. Age & 16.90 & .82 & $.06^{*}$ & $.08 * *$ & & & & & & & & & & & & \\
\hline $\begin{array}{l}\text { 4. Race } \\
\text { (1=White) }\end{array}$ & .71 & .45 & $.16^{* * *}$ & .00 & .05 & & & & & & & & & & & \\
\hline 5. Income & 6.23 & 2.89 & $.17 * * *$ & -.02 & .02 & $.27 * * *$ & & & & & & & & & & \\
\hline $\begin{array}{l}\text { 6. Parental } \\
\text { religiosity }\end{array}$ & 4.22 & 1.53 & $-.06^{*}$ & -.01 & .01 & $-.11 * * *$ & -.05 & & & & & & & & & \\
\hline $\begin{array}{l}\text { 7. Parental } \\
\text { monitoring }\end{array}$ & 2.59 & 1.23 & $-.13 * * *$ & -.02 & $-.21 * * *$ & -.03 & $-.06^{*}$ & $.21 * * *$ & & & & & & & & \\
\hline $\begin{array}{l}\text { 8. Adolescent } \\
\text { religiosity }\end{array}$ & 3.61 & 1.57 & $-.19 * * *$ & $.13 * * *$ & .02 & $-.07 *$ & $-.09 * *$ & $.53 * * *$ & $.31 * * *$ & & & & & & & \\
\hline 9. Evangelical & .34 & .47 & $-.11 * * *$ & $.06^{*}$ & .01 & -.04 & $-.11 * * *$ & $.29 * * *$ & $.14 * * *$ & $.47 * * *$ & & & & & & \\
\hline 10. LDS & .02 & .14 & -.02 & .00 & .02 & .03 & -.01 & $.10 * * *$ & $.08 * *$ & $.12 * * *$ & $-.10 * * *$ & & & & & \\
\hline $\begin{array}{l}\text { 11. Mainline } \\
\text { Protestant }\end{array}$ & .10 & .30 & .07 & .02 & $.07 *$ & $.10 * * *$ & $.17 * * *$ & $.06^{*}$ & -.02 & $.06^{*}$ & $-.24 * * *$ & -.05 & & & & \\
\hline 12. Catholic & .20 & .40 & .03 & -.02 & -.01 & -.04 & $.07 *$ & .01 & -.03 & $-.09 * *$ & $-.35 * * *$ & $-.07 *$ & $-.16 * * *$ & & & \\
\hline 13. Jewish & .04 & .19 & $.06^{*}$ & .03 & -.02 & $.10 * * *$ & $.20 * * *$ & $-.09 * *$ & -.01 & $-.16^{* * *}$ & $-.14 * * *$ & -.03 & $-.07 *$ & $-.10 * * *$ & & \\
\hline 14. Aggression & 1.45 & .78 & .03 & $-.24 * * *$ & $-.10 * * *$ & $-.11 * * *$ & $-.16 * * *$ & -.05 & $-.10 * * *$ & $-.10 * * *$ & .00 & -.01 & $-.07 *$ & -.04 & $-.08 * *$ & \\
\hline $\begin{array}{l}\text { 15. Attitude } \\
\text { about sex }\end{array}$ & 1.13 & .85 & $.20 * * *$ & $-.16 * * *$ & .05 & -.02 & $.09 * *$ & $-.29 * * *$ & $-.31 * * *$ & $-.58 * * *$ & $-.28 * * *$ & $-.09 * *$ & -.02 & $.09 * *$ & $.12 * * *$ & $.19 * * *$ \\
\hline
\end{tabular}


Table 2

Summary of Hierarchical Regression Analysis for Variables Predicting Television Maturity Mean $(n=1,242)$

\begin{tabular}{|c|c|c|c|c|c|c|c|c|c|}
\hline \multirow[b]{2}{*}{ Variable } & \multicolumn{3}{|c|}{ Step 1} & \multicolumn{3}{|c|}{ Step 2} & \multicolumn{3}{|c|}{ Step 3} \\
\hline & $B$ & $S E B$ & $\beta$ & $B$ & $S E B$ & $\beta$ & $B$ & $S E B$ & $\beta$ \\
\hline Gender (1=Female) & -.27 & .04 & $-.17 * * *$ & -.25 & .04 & $-.16^{* * *}$ & -.23 & .05 & $-.15 * * *$ \\
\hline Age & .04 & .03 & .04 & .05 & .03 & .05 & .04 & .03 & .05 \\
\hline Race (1=White) & .16 & .03 & $.09 * *$ & .16 & .05 & $.09 * *$ & .17 & .05 & $.10^{* *}$ \\
\hline Income & .04 & .01 & $.13 * * *$ & .03 & .01 & $.12 * * *$ & .03 & .01 & $.11 * * *$ \\
\hline Parental religiosity & -.02 & .01 & -.04 & .01 & .02 & .03 & .02 & .02 & .03 \\
\hline Parental monitoring & -.07 & .02 & $-.11 * *$ & -.05 & .02 & $-.08 *$ & -.04 & .02 & -.06 \\
\hline $\begin{array}{l}\text { Parental religiosity } \times \\
\text { Parental monitoring }\end{array}$ & .01 & .01 & .01 & .01 & .01 & .03 & .01 & .01 & .03 \\
\hline Adolescent religiosity & & & & -.07 & .02 & $-.14 * * *$ & -.04 & .02 & $-.08 *$ \\
\hline Evangelical & & & & -.03 & .07 & -.02 & -.04 & .07 & -.02 \\
\hline LDS & & & & -.07 & .17 & -.01 & -.07 & .17 & -.01 \\
\hline Mainline Protestant & & & & .13 & .07 & .05 & .11 & .08 & .04 \\
\hline Catholic & & & & .04 & .07 & .02 & .03 & .07 & .01 \\
\hline Jewish & & & & .08 & .09 & .02 & .06 & .09 & .01 \\
\hline $\begin{array}{l}\text { Adolescent religiosity } \times \\
\text { Parental monitoring }\end{array}$ & & & & .01 & .01 & .02 & -.002 & .01 & -.01 \\
\hline Aggression & & & & & & & -.0003 & .03 & -.0003 \\
\hline Attitude about sex & & & & & & & .09 & .04 & $.10^{* *}$ \\
\hline$R^{2}$ & & & .086 & & & .105 & & & .111 \\
\hline$\Delta R^{2}$ & & & & & & $.019 * *$ & & & $.006 * *$ \\
\hline$n$ & & & 1234 & & & 1227 & & & 1225 \\
\hline
\end{tabular}

$* p<.05, * * p<.01, * * * p<.001$ 
